\title{
Commentary: Reintervention on failed aortic homografts-Sutureless, suture more, or suture not at all
}

\author{
Joanna Chikwe, MD, ${ }^{a, b}$ and Puja B. Parikh, $\mathrm{MD}^{\mathrm{c}}$
}

\footnotetext{
From the a Department of Cardiovascular Surgery, Mount Sinai Medical Center, New York, NY; Departments of ${ }^{\mathrm{b}}$ Surgery and ${ }^{\mathrm{c}}$ Medicine, The State University of New York, Stony Brook, NY.

Disclosures: Dr Chikwe has received speaker honoraria from Edwards Lifesciences. Dr Parikh has nothing to disclose with regard to commercial support.

Received for publication Jan 6, 2019; accepted for publication Jan 7, 2019; available ahead of print Feb 22, 2019. Address for reprints: Joanna Chikwe, MD, Department of Cardiovascular Surgery, Mount Sinai Medical Center, 1190 Fifth Ave, New York, NY 10029 (E-mail: Joanna.Chikwe@mountsinai.org).

J Thorac Cardiovasc Surg 2019;158:386-7

$0022-5223 / \$ 36.00$

Copyright (C) 2019 Published by Elsevier Inc. on behalf of The American Association for Thoracic Surgery https://doi.org/10.1016/j.jtcvs.2019.01.018
}

In this issue of the Journal, Sedeek and colleagues ${ }^{1}$ report their study of 51 patients undergoing reintervention for failed aortic homografts during an 18-year experience at the Mayo Clinic. Their findings highlight several useful lessons.

First, homografts provide limited freedom from reintervention: reoperations occurred on average 12 years after implantation, as opposed to 8 years in a larger series from Germany. ${ }^{2}$ Second, surgery for homograft failure is challenging even for experienced centers. In the 40 patients reoperated on by the Mayo team, challenges included sternal reentry injuries in $15 \%$, need for root replacement in $75 \%$ (with Cabrol modifications in $17 \%$ ), major bleeding in $58 \%$, and mechanical support in $15 \%$. There were 3 procedural deaths in the surgical group $(8 \%)$. Homograft degeneration causes diffuse, eggshell calcification and a narrow annulus in rigid aortic roots, often requiring endarterectomy, annular enlargement, or root replacement to allow suture placement and prosthesis implantation. Calcification limits mobilization of coronary buttons, necessitating Cabrol grafts to restore continuity between the aortic root and coronary ostia. There are 3 series in the literature with operative mortalities lower than $5 \%$, and all favored redo valve rather than root replacement of the homograft. $^{2-4}$

Third, transcatheter valve-in-valve replacement for the failed homograft is not necessarily a lower risk alternative to surgery. Homograft root geometry may be very distorted. Sedeek and colleagues ${ }^{1}$ describe an inverted conical outflow, making it difficult to size and position a transcatheter prosthesis. Lack of annular calcification (or a metal stent) prevents easy identification of a landing zone by fluoroscopy and increases the risk of device migration and embolization. For this reason, an oversized self-expanding prosthesis has been the preferred choice; however, this increases the risk of coronary obstruction, particularly in patients with low-lying coronary ostia in

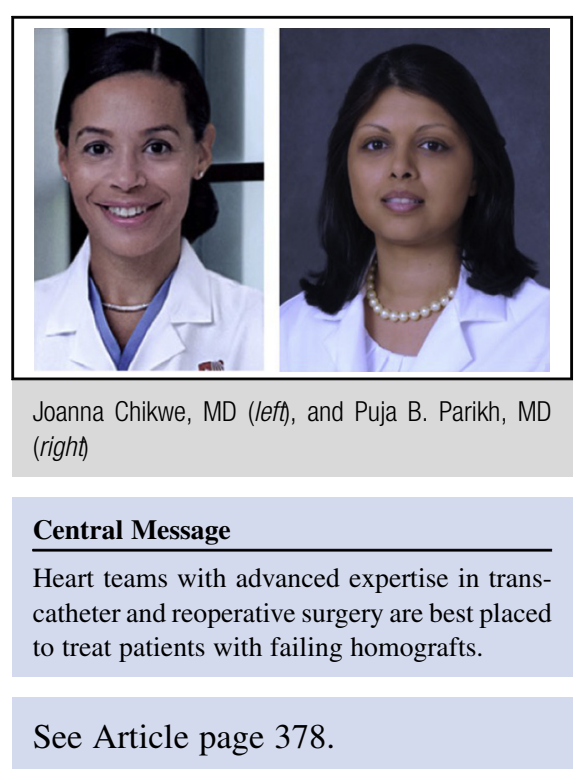

narrow roots or with a homograft that was implanted with a subcoronary rather than a root replacement technique. Significant aortic regurgitation, common in homograft degeneration, reduces valve stability during deployment. Procedural success thus requires a detailed understanding of root anatomy, including the homograft size and implantation technique, transesophageal echocardiographic and fluoroscopic guidance, and rapid pacing during deployment, with the options for retrieval, percutaneous coronary rescue, and surgical bailout. Procedural mortality for valve-in-valve intervention on failed stentless prostheses and aortic homografts is also $5 \%$ to $10 \%$. $^{5}$

Finally, rapid deployment aortic valves (not used in this series) are an important addition to treatment options. The benefits of redo valve compared to root replacement for failed homografts are captured in a series of 90 patients operated on between 1992 and 2009 in Munich University Hospital. $^{2}$ After exclusion of patients with endocarditis, there was no operative mortality in the 80 patients who had redo aortic valve replacement with traditional prosthetic valves. Compared with traditional prosthetic valves, rapid deployment valves need few or no annular sutures and have a significantly better hemodynamic profile. Early experience suggests that these aspects may increase the feasibility of aortic valve replacement in failed homografts.

There is no single solution for patients with failed homografts. Heart teams with experience in all surgical and 
transcatheter options are best suited to manage this small and diminishing pool of challenging patients.

\section{References}

1. Sedeek AF, Greason KL, Nkomo VT, Eleid MF, Maltais S, Williamson EE, et al. Repeat aortic replacement for failing aortic root homograft. J Thorac Cardiovasc Surg. 2019;158:378-85.e2.

2. Kowert A, Vogt F, Beiras-Fernandez A, Reichart B, Kilian E. Outcome after homograft redo operation in aortic position. Eur J Cardiothorac Surg. 2012;41:404-8.
3. Khalpey A, Borstlap W, Myers PO, Schmitto JD, McGurk S, Maloney A, et al. The Valve-in-valve operation for aortic homograft dysfunction: a better option. Ann Thorac Surg. 2012;94:731-5; discussion 735-6.

4. Sadowski J, Kapelak B, Bartus K, Podolec P, Rudzinski P, Myrdko T, et al. Reop eration after fresh homograft replacement: 23 years' experience with 655 patients. Eur J Cardiothorac Surg. 2003;23:996-1000; discussion 1000-1.

5. Choi CH, Cheng V, Malaver D, Kon N, Kincaid EH, Gandhi SK, et al. A comparison of valve-in-valve transcatheter aortic valve replacement in failed stemless versus stented surgical bioprosthetic aortic valves. Catheter Cardiovasc Interv. December 27, 2018 [Epub ahead of print]. 